\title{
TEKNOLOGI MARKETPLACE SEBAGAI UPAYA PENINGKATAN PEMASARAN PRODUK HASIL USAHA KECIL
}

\author{
Cahya Vikasari
}

Program Studi Teknik Informatika, Politeknik Negeri Cilacap cvikasari@gmail.com ${ }^{1}$

\begin{tabular}{|c|c|}
\hline & Abstrak \\
\hline $\begin{array}{l}\text { Kata Kunci: } \\
\text { Marketplace; Target; } \\
\text { Pemasaran. }\end{array}$ & $\begin{array}{l}\text { Usaha kecil menengah sangat berkembang pesat di Indonesia. Salah satu kegiatan yang ada pada } \\
\text { usaha kecil menengah tersebut adalah proses pemasaran. Para pengusaha cenderung fukos pada } \\
\text { kegiatan produksi tetapi untuk strategi pemasaran tidak terlalu dikembangkan sehingga pangsa } \\
\text { pasarnya masih pasar lokal. Permasalahan yang terjadi dalam pemasaran produk usaha kecil } \\
\text { menengah adalah pengetahuan yang sedikit mengenai strategi pemasaran, target pemasaran dan } \\
\text { kemauan untuk berkembang dari pengusaha itu sendiri. Sistem marketplace dibangun untuk } \\
\text { meningkatkan perluasan pasar sehingga dapat membantu para pengusaha untuk melakukan } \\
\text { pemasaran. Sistem marketplace dibangun berbasis web, baik pengusaha maupun pembeli dapat } \\
\text { berkomunikasi melalui web marketplace tersebut. Hasil penelitian dari penelitian ini adalah sistem } \\
\text { dapat menjangkau pemasaran yang lebih luas dengan marketplace usaha kecil menengah dan lebih } \\
\text { targeted. }\end{array}$ \\
\hline
\end{tabular}

\begin{tabular}{|c|c|}
\hline & Abstract \\
\hline $\begin{array}{l}\text { Keywords: } \\
\text { Marketplace; Target; } \\
\text { Marketing. }\end{array}$ & $\begin{array}{l}\text { Small and medium businesses are very rapidly growing in Indonesia. One of the activities in the small } \\
\text { and medium business is the marketing process. The entrepreneurs tend to focus on production activities } \\
\text { but for marketing strategies are not developed so that the market share is still local market. The } \\
\text { problems that occur in marketing small and medium business products are little knowledge about } \\
\text { marketing strategies, marketing targets and willingness to develop from the entrepreneurs themselves. } \\
\text { Marketplace systems are built to increase market expansion so that it can help entrepreneurs to do } \\
\text { marketing. The marketplace system is built based on the web, both entrepreneurs and buyers can } \\
\text { communicate through the web marketplace. The results of this study are that the system can reach } \\
\text { broader marketing with small and medium business marketplaces and more targeted. }\end{array}$ \\
\hline
\end{tabular}

\footnotetext{
$\varpi$ Alamat korespondensi :jl.Dr.Soetomo No.1 Sidakaya Cilacap

E-mail : cvikasari@gmail.com

ISSN : 2087-1627
} 


\section{Pendahuluan}

Perkembangan usaha kecil menengah sangat pesat di Indonesia akan tetapi para pengusaha masih fokus pemasaran di wilayah lokal daerah tempat produksi. Salah satu faktor yang membuat para pengusaha lokal ini kurang bersaing dalam hal pemasaran dan kurang mengembangkan pemasarannya dikarenakan pemasaran masih dilakukan secara offline misalnya untuk menjual suatu produk UKM biasanya konsumen yang membutuhkan produk datang langsung ke tempat produksi dan membeli produk yang diinginkan. Pada umumnya, penjualan produk UKM yang dilakukan secara offline hanya bisa melayani konsumen pada daerah tertentu saja. Produk dari UKM memiliki harga yang terjangkau dan mempunyai kualitas yang bagus akan berdampak pada konsumen yaitu menjadi pelanggan yang setia dan jika konsumen memiliki pengalaman pelayanan yang baik dari pemasaran tersebut nantinya akan mempunyai dampak promosi positif dengan disebarkan dari mulut ke mulut. Namun jangkauan pemasarannya lebih sempit karena hanya pada orang-orang terdekat di sekitarnya.

Kewirausahaan merupakan sebuah nilai yang diwujudkan kedalam perilaku yang akan dijadikan dasar dari sumber daya, proses, tujuan, tenaga penggerak, siasat, kiat, dan hasil bisnis. Hasil dari usaha juga belum dapat dikatakan berhasil jika tidak melakukan kegiatan pemasaran dengan baik. Pemasaran merupakan kegiatan untuk meneliti kebutuhan serta keinginan dari konsumen, memproduksi barang atau jasa, menentukan harga sebuah produk, mempromosikan dan mendistribusikan ke konsumen [1]. Teknik terbatas yang dimiliki pengusaha dalam mendukung perluasan penjualan produk usaha kecil menengah perlu adanya perubahan dalam melakukan pemasaran agar para pengusaha dapat melaksanakan pemasaran yang lebih luas yang diharapkan dapat meningkatkan kesejahteraan masyaraka. Kesalahan dalam melakukan pemasaran antara lain timing ( pemilihan waktu), pesan iklan yang tidak sampai pada konsumen, cara promosi yang kurang tepat, tidak mengukur efektivitas promosi, data yang tidak up-to-date, hanya menggandalkan satu media untuk beriklan, kurangnya komunikasi dengan konsumen [2].

Promosi mengenai produk UKM juga tidak terlepas dari peran kemasan yang baik dalam mendukung perluasan pasar. Adanya kemasan atau packaging yang baik akan menjadi media komunikasi / promosi yang mendongkrak hasil penjualan, karena packaging sebuah produk pada saat ini mengalami pergeseran fungsi yang pada awalnya hanya melindungi sebuah produk, kini mulai berfungsi sebagai identifikasi sebuah merk dagang. Perkembangan kemasan pada akhirnya menjadi bagian ujung tombak dari proses promosi suatu produk yang pada akhirnya berfungsi untuk meningkatkan nilai jual produk tersebut.

Teknologi yang sangat pesat juga dapat digunakan untuk melakukan pemasaran dan tujuan untuk memperluas pemasaran dapat dilakukan dengan bantuan teknologi. Berdasarkan alasan di atas penulis tertarik untuk melakukan penelitian teknologi marketplace yang merupakan bagian dari digital marketing yang dapat digunakan untuk memperluas pemasaran produk UKM. Penelitian yang diangkat adalah Teknologi Marketplace Dalam Peningkatan Pemasaran Produk Hasil Usaha Kecil.

\section{Tinjauan Pustaka}

Marketplace adalah sebuah model bisnis
online yang akan membantu dalam mempromosikan produk yang dijual serta memfasilitasi transaksi uang yang dilakukan secara online. Marketplace menyediakan beberapa produk dari penjual secara online[3]. Teknik yang mempermudah akses dan publikasi informasi dengan cara menggunakan interaksi social yaitu social media[4]. Kemudian jurnal yang berjudul pemanfaatan social media untuk meningkatkan market share UKM membahas mengenai dua jenis pemasaran, yaitu pemasaran tradisional atau offline marketing yang dilakukan dengan melakukan pencarian pelanggan melalui pertemuan yang dilakukan secara langsung berhadapan dengan mereka yang mungkin pelanggan tersebut tertarik menjadi klien atau pelanggan. Pemasaran yang lain menggunakan situs web sebagai media untuk melakukan pemasaran secara online atau yang dikenal sebagai online marketing [5].

Penjualan merupakan sebuah ilmu serta seni yang mempengaruhi pribadi, yang dilakukan oleh penjual, untuk mengajak orang lain atau pelanggan bersedia membeli barang atau jasa yang ditawarkan kepada pembeli. Jumlah penjualan adalah jumlah barang atau jasa yang terjual dalam proses pertukaran. Jumlah dari penjualan dalam penelitian ini merupakan jumlah dari produk yang terjual dalam penjualan yang dilakukan. Home industry adalah sebuah usaha kecil yang pekerjanya merupakan anggota keluarga secara langsung terlibat dalam jabatan, kepemilikan dan fungsi. Usaha keluarga mempunyai karakteristik dengan kepemilikannya atau keterlibatan lainnya dari dua peran atau lebih anggota keluarga yang sama dalam kehidupan dan fungsi bisnisnya[6].

Tujuh tahapan dalam membuat perancangan emarketing yaitu [7] :

1. Situation Analysis (Analisis Situasi)

2. EMarketing Strategic Planning (Strategi Perencanaan E-Marketing)

3. Objectives (Tujuan) 
4. E-Marketing Strategy (Strategi EMarketing)

5. Implementation Plan (Rencana Pelaksanaan)

6. Budget (Anggaran)

7. Evaluation Plan (Rencana Evaluasi).

\section{Metode Penelitian}

Metode penelitian yang akan dilaksanakan dalam penelitian ini mengikuti tahap pengembangan perangkat lunak dengan metode prototyping. Ogedebe, dkk (2012), menyampaikan bahwa metode pengembangan prototyping merupakan metode yang berupa model fisik kerjadari sebuah sistem yang berfungsi sebagai versi awal dari sistem. Dengan menggunakan metode prototyping maka akan dihasilkan prototype sistem sebagai perantara dan sebagai media komunikasi antara pengembang dan pengguna atau end user agar dapat berinteraksi dalam kegiatan pengembangan perangkat lunak. Langkah-langkah yang akan dilakukan dengan menggunakan metode prototyping adalah sebagai berikut[8] :

1. Pengumpulan Kebutuhan.

2. Proses desain yang cepat.

3. Membangun prototipe.

4. Evaluasi dan perbaikan.

Pembuatan teknologi akan memperhitungkan metode perluasan pasar yaitu harus memperhitungkan aktifitas internet pengusaha karena kan terlihat pengusaha aktif mengecek halaman toko nya sehingga akan meningkatkan tingkat kepercayaan pelanggan terhadap toko dari UKM yang berdiri, segmentasi atau target pasar harus mengarah ke segmen pasar yang sesuai dengan produknya, deferensiasi kompetitif untuk para pelaku usaha yang melakukan pemasaran pada marketplace.

\section{Hasil Penelitian}

Requirement atau fungsi utama yang dibutuhkan dalam teknologi marketpace dalam meningkatkan perluasan pasar yang diperoleh dari tahap pengumpulan kebutuhan yaitu :

A. Kebutuhan fungsional

a. Fungsi segmentasi pasar agar penjualan sesuai target pasar

b. Aktifitas pengusaha untuk menggambarkan aktif tidaknya pengusaha dalam mengelola toko

c. Aktifitas penjualan yaitu untuk pengolahan administrasi penjualan

d. Flash sale/obral untuk meningkatkan penjualan

e. Deferensiasi kompetitif.

f. Pengelolaan data toko berdasarkan akun masing-masing pengusaha.
B. Non functional

Setelah mendeskripsikan kebutuhan fungsional, maka langkah selanjutnya adalah mendeskripsikan apa saja yang kebutuhan dari nonfungsional. Kebutuhan non fungsional merupakan batasan fungsi atau layanan yang ditawarkan oleh sistem seperti batasan pengembangan dari proses, batasan waktu, standarisasi,dll. Berbeda dengan kebutuhan fungsional, kebutuhan non fungsional lebih kritis karena jika kondisi non fungsional tidak terpenuhi maka sistam atau aplikasi tidak berguna. Hal ini perlu dideskripsikan agar dapat mendukung pelaksanaan dari kebutuhan fungsional. Berikut adalah informasi detil dari kebutuhan nonfungsional:

1. Web Development dalam pengembangan website marketplace menggunakan bahasa PHP, HTML, dan script lainnya dalam merancang interface, Database MySQL.

2. Kebutuhan Perangkat Keras (Hardware) Kebutuhan akan perangkat keras tidak di lakukan spesifikasikan secara khusus karena penelitian tidak tidak meneliti mengenai pemilihan hardware. Perangkat yang akan digunakan untuk mengakse sistem marketplace minimal dapat mengakses internet.

3. Aplikasi market place dapat diakses oleh pembeli secara bersamaan dan server akan tetap stabil. Sistem juga akan tetap stabil dan beroperasi pada saat pembeli secara bersamaan memproses pembelian dan dilain pihak penjual juga akan memproses penjualannya.

4. Kebutuhan Perangkat Lunak (Software)

Kebutuhan perangkat lunak dalam pengembangan perangkat lunak dapat dilihat pada tabel 1 .

Tabel 1.Kebutuhan Perangkat Lunak

\begin{tabular}{|l|l|l|}
\hline No & Jenis Aplikasi & Software \\
\hline 1 & Sistem Operasi & Windows 7 \\
\hline 2 & Text Editor & $\begin{array}{l}\text { Adobe Photoshop } \\
\text { CS } \\
\text { Edit Plus }\end{array}$ \\
\hline 3 & $\begin{array}{l}\text { Software } \\
\text { Pendukung }\end{array}$ & XAMPP 1.7.7 \\
\hline 4 & Web browser & Mozilla Firefox \\
\hline 5 & Web server & Apache 1.3.2 \\
\hline 6 & Database server & MySQL Versi 5 \\
\hline
\end{tabular}

Proses berikutnya yaitu tahapan desain yang dapat dilakukan dengan lebih cepat dengan metode pengembangan perangkat lunak prototyping.desain digambarkan dengan data flow diagram. Data Flow Diagram (DFD) merupakan alat pembuatan desain yang akan memungkinkan profesional sistem untuk dapat menggambarkan sistem menjadi suatu jaringan proses dari fungsional yang berfungsi untuk dihubungkan satu sama lain dengan aliran data, baik secara manual maupun komputerisasi [9]. 
Data flow diagram sitem marketplace usaha kecil menengah dapat dilihat pada gambar 1 .

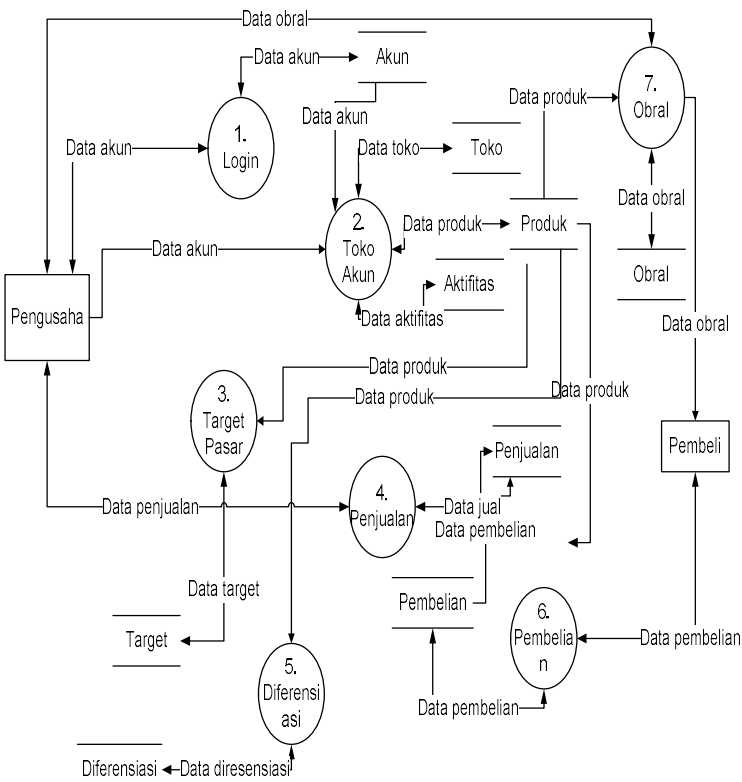

Gambar 1. Data flow Diagram Marketplace

Architecture vision adalah tahap yang mendefinisikan ruang lingkup, membuat visi arsitektur, melakukan identifikasi dari stakeholder. Salah satu architecture vision yang peneliti buat dalam pengembangan aplikasi marketplace untuk UKM dengan tujuan untuk memperluas pasar usaha kecil menengah adalah solution concept diagram yang akan menggambarkan high level dari kegiatan marketplace dalam memperluas pemasaran. Berikut merupakan penggambaran dari solution concept diagram model marketplace usaha kecil menengah. Langkah-langkah yang harus dilakukan yaitu[10] mendapatkan data dan informasi mengenai latar belakang dalam pembangunan sistem, sistem yang sedang berjalan pada proses pemasaran, peran stakeholder dan ruang lingkup proses bisnis perusahaan, mengetahui profil, visi, misi dan tujuan untuk menentukan tujuan bisnis perusahaan, langkah terakhir yaitu proses bisnis dari aktivitas utama dari marketplace UKM dalam memperluas pemasaran. Berikut gambar dari architecture vision dapat dilihat pada gambar 2 .

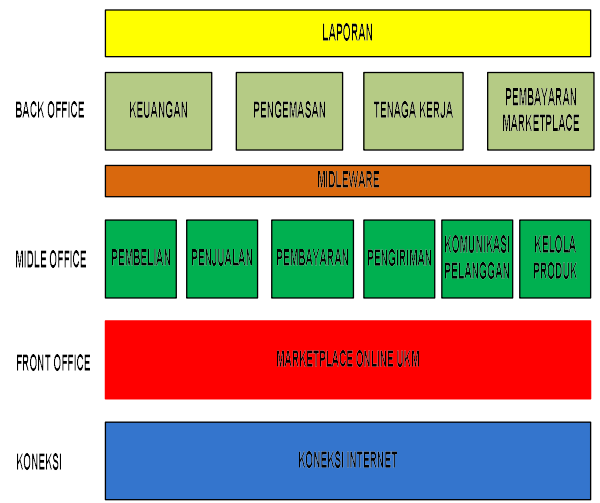

Gambar 2. Architecture Vision

Arsitektur jaringan yang dibangun untuk membentuk marketplace dibuat untuk komunikasi jaringan untuk pengusaha usaha kecil menengah dan para pembelinya. Pembeli akan mencari produk yang mereka butuhkan dan web marketplace yang akan melayani pembeli tersebut. Penjual akan melakukan pendataan mengenai data penjualan dan akan memproses penjualan tersebut yang diambil datanya dari web marketplace. Arsitektur jaringan sistem marketplace dapat dilihat pada gambar 3 .

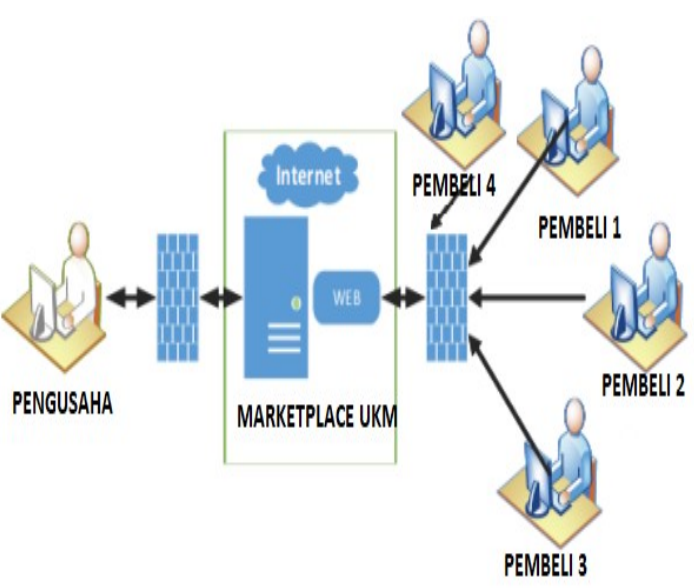

Gambar 3. Arsitektur Jaringan

Desain user interface dari sistem aplikasi marketplace dibuat sederhana dengan tujuan pembeli akan fokus terhadap barang yang dicari dan fungsi-fungsi yang mendukung untuk proses pembelian oleh pelanggan. Fasilitas pencarian barang digunakan untuk pembeli yang sudah mengetahui barang apa yang akan dicari, aplikasi juga menangani pembeli yang sebelumnya tidak tahu apa yang ingin pembeli beli yaitu memberikan fitur promo dan obral, dengan fitur ini diharapkan pembeli tertarik dengan barang yang sedang di promokan atau obral. Tampilan antar muka dapat dilihat pada gambar 4 .

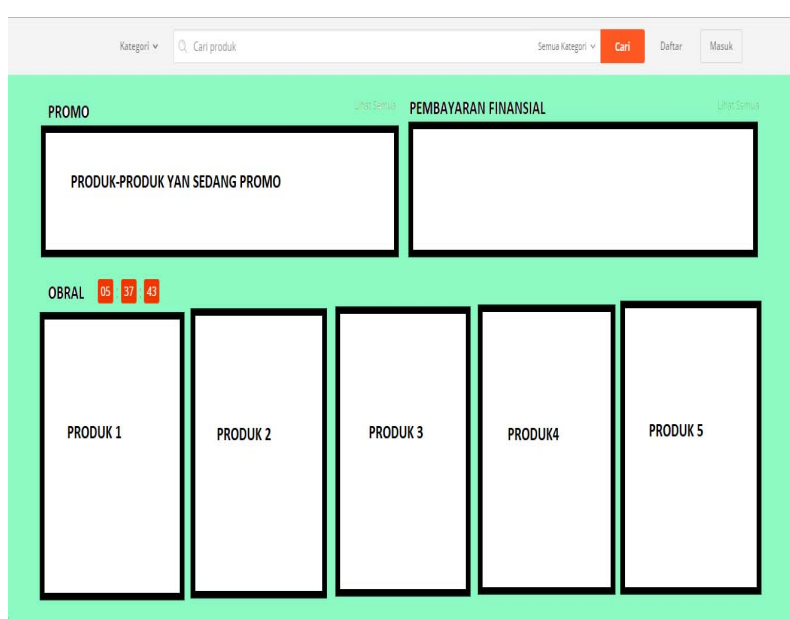

Gambar 3. Desain Halaman Utama Market Place 
Sistem marketplace untuk usaha kecil menengan dibuat dengan akses pembeli dengan skala luas, dengan fasilitas internet yang kini sudah menjangkau seluruh negeri sehingga pemasaran produk UKM dapat memperluas wilayah pemasaran. Marketplace ini juga mempunyai fasilitas untuk menawarkan produk yang sedang promo dan fasilitas obral produk sehingga aplikasi dapat menarik pembeli yang belum niat untuk membeli produk dapat tertarik dengan produk tersebut. Menu pencarian produk dapat digunakan oleh calon pembeli yang sudah memiliki tujuan untuk mencari atau membeli produk tertentu. Sistem marketplace sangat membantu para pengusaha untuk melakukan pemasaran karena proses pemasaran untuk mendapatkan pelanggan dengan skala yang lebih luas dan terdapat segmentasi pasarnya, menghandle pemesanan akan dilakukan oleh sistem sehingga pengusaha dapat lebih fokus untuk pengembangan usaha dan produksi. Aplikasi sangat membantu pemasaran namun hal ini juga harus ada peran serta dari para pengusaha untuk membuat kemasan produk dan deskripsi produk dengan menarik agar hasil dari pemasaran sesuai dengan yang diharapkan.

\section{Kesimpulan}

Kesimpulan dari kegiatan penelitian mengenai teknologi marketplace sebagai upaya peningkatan pemasaran produk hasil usaha kecil adalah sebagai berikut :

1. Sistem dapat menjangkau pemasaran yang lebih luas dengan marketplace UKM.

2. Sistem dapat melakukan pemasaran dengan lebih targeted sehingga diharapkan pelanggan akan meneruskan ke proses pembelian produk.

3. Kemasan produk dapat menarik pelanggan sehingga produk UKM harus mempunyai standar kemasan yang baik.

\section{Daftar Pustaka:}

[1] Dzkwaan Priaji, "Pengertian Kewirausahaan Menurut Ahli," 2013. [Online]. Available: http://zakwaanpriaji.blogspot.com/2013/07/pengertiankewirausahaan-menurut-ahli.html.

[Accessed: 20-Sep-2018].

[2] Sri Warni, "7 Kesalahan Dalam Pemasaran Yang Sering Terjadi." [Online]. Available: https://zahiraccounting.com/id/blog/7kesalahan-dalam-pemasaran-yang-seringterjadi/. [Accessed: 20-Sep-2018].

[3] A. Khumaidi, "Perancangan Aplikasi Marketplace Order Baju Pintar Menggunakan Web Responsif Untuk Memudahkan Customer Mendesain Sesuai Selera," Ikraith-Informatika, Vol. 2, No. 2, 2018.
[4] J. Sarwono and A. H. Prihartono, Perdagangan Online: Cara Bisnis di Internet. Jakarta: PT Elex Media Komputindo, 2012.

[5] A. B. P. Irianto and E. Nugrogo, "Media Sosial dalam Meningkatkan Market Share UKM dan Pencurian Informasi," 2014, pp. 127-133.

[6] T. Pradiani, V. Penjualan, and S. Malang, "TERHADAP PENINGKATAN VOLUME PENJUALAN HASIL," JIBEKA, vol. 11, pp. 46-53, 2017.

[7] Strauss Judy and R. Frost, E-Marketing, 5th Editio. New Jersey: Prentice-Hall, Inc., 2009.

[8] D. Purnomo, "Model Prototyping Pada Pengembangan Sistem Informasi," JIMP J. Inform. Merdeka Pasuruan, vol. 2, no. 2, pp. 54-61, 2017.

[9] Darmastuti, "Data Flow Diagram." [Online]. Available: darmastuti.staff.gunadarma.ac.id/Download s/files/59129/Data+Flow+Diagram.pdf\%0A . [Accessed: 29-Oct-2018].

[10] I. N. Aulia and I. K. R. Purbandini, "Perencanaan Arsitektur Perusahaan pada Bagian Instalasi Rawat Jalan dengan Kerangka Kerja TOGAF ADM," J. Inf. Syst. Eng. Bus. Intell., vol. 3, no. 1, 2017. 